\title{
Direito à educação, universalização e qualidade: cenários da Educação Básica e da particularidade do Ensino Médio ${ }^{1}$
}

\author{
Right to education, universal access and quality: Basic \\ Education scenarios and high school particularity
}

\author{
Derecho a la educación, acesso universal y calidad: escenarios \\ de Educación Básica y la particularidad de la escuela secundaria
}

\section{Monica Ribeiro da Silva²}

\section{Resumo}

O texto faz inicialmente uma discussão conceitual sobre direito à educação. Em seguida, aborda a problemática que cerca esse direito com base no que determinam a Constituição Federal de 1988, a Lei de Diretrizes e Bases da Educação de 1996 e o Plano Nacional de Educação 2014-2024. Traz dados sobre a oferta da educação básica e os analisa à luz do princípio constitucional do direito e do dever do Estado. A partir dessa análise discute a problemática da universalização do Ensino Médio e do acesso à escola por parte das juventudes brasileiras.

Palavras chave: Direito a Educação; Educação Básica; Ensino Médio; Universalização; Política educacional.

\begin{abstract}
The text initially does a conceptual discussion about the right to education. Then, it addresses the issues surrounding this right on the basis of what was determinated by 1988 Federal Constitution, the National Law of Education of 1996 and the National Education Plan 2014-2024. It brings data on the supply of basic education and analyzes them face to the constitutional principle of the right and the duty of the State. From this analysis, the article discusses the issue of universalization of secondary education and access to school by Brazilian youths.
\end{abstract}

Keywords: Right to Education; Basic education; High school; Universalization; Educational policies.

\section{Resumen}

El texto hace inicialmente una discusión conceptual del derecho a la educación. A continuación, aborda las cuestiones relacionadas con este derecho sobre la base de la determinación de la Constitución Federal de 1988, la Ley de Directrices y Bases de la Educación de 1996 y el Plan Nacional de Educación 2014-2024. Aporta datos sobre la oferta de educación básica y analiza la luz del principio constitucional del derecho y el deber del Estado. A partir de esto se analiza la cuestión de la universalización de la educación secundaria y el acceso a la escuela por los jóvenes brasileños.

Palabras clave: Derecho a la Educación; Educación básica; Enseñanza secundária; Universalización; Política educativa.

1 Texto preparado com vistas à participação no II Colóquio Docência e Diversidade na Educação Básica: políticas, práticas e formação. Salvador/BA, 19 a 21 de maio de 2015.

2 Doutora em Educação. Professora e pesquisadora do PPGE/UFPR. E-mail: monicars@ufpr.br 


\section{Um início de conversa}

Escrevo este texto e me preparo para o II Colóquio Docência e Diversidade na Educação Básica: políticas, práticas e formação" em meio à proliferação de greves de educadores por todo o país. Neste maio de 2015, estão em andamento mobilizações paredistas em pelo menos quatro capitais e em cinco redes estaduais de ensino. Atenho-me neste início de reflexão à greve dos professores da rede estadual paranaense, haja vista a agressão física e moral sofrida pelos educadores desse estado no último 29 de abril.

A situação na cidade de Curitiba, capital do estado do Paraná, beirou a catástrofe. Os professores da Educação Básica, da educação superior e servidores das áreas da saúde, do judiciário, dentre outros entraram em greve, pois o governo do estado, falido pelo atual e reeleito governador, enviou para a Assembleia Legislativa do Paraná (ALEP) um Projeto de Lei (PL 252/2015) que o autorizaria a transferir recursos da previdência dos servidores para o caixa do governo, na ordem de 125 milhões por mês. Em 4 anos, o rombo na Paraná Previdência seria de aproximadamente 8 bilhões de reais.

A mobilização docente havia se iniciado em fevereiro deste mesmo ano, momento em que, após aproximadamente 30 dias de greve, se fizera um acordo que culminou com a retomada das aulas, porém, com a manutenção do "estado de greve" por parte dos educadores. Pelo acordo, o Projeto de Lei seria retirado da pauta pelo governo, o que foi cumprido de imediato, todavia, reencaminhado no mês de abril. Em 25 de abril, os profissionais da educação deliberaram em assembleia pela retomada da greve. Na tarde do dia 28 de abril, com vistas a intimidar os educadores acampados em frente à Assembleia Legislativa, ocorrera uma ação de violência por parte dos policiais militares convocados a impedir a aproximação do prédio da ALEP. Houve o uso de bombas de gás lacrimogêneo, spray de pimenta, jatos de água e corpo a corpo protagonizado pela tropa de choque da Polícia Militar contra os professores e os demais servidores se firmaria como prenúncio do terror protagonizado no dia seguinte, data marcada para votação do PL.

Contrariando todas as regras estabelecidas, os policiais estavam fortemente armados e foram chamados de todas as regiões do estado para cercar a ALEP. Isso porque, em fevereiro, os professores haviam ocupado o prédio da Assembleia Legislativa e conseguido impedir que a Lei fosse votada. No dia 29 de abril, contavam na Praça Nossa Senhora da Salete, em frente à ALEP e ao Palácio do Governo, mais de dois mil policiais. E lá estavam também professores vindos de toda a parte do estado para proteger o que é seu por direito. A tensão foi alimentada por helicópteros voando baixo, presença da cavalaria e da tropa de choque da Polícia Militar.

Enquanto na Praça educadores eram agredidos, dentro da Assembleia Legislativa os deputados da base governista insistiam na aprovação do Projeto de Lei. Foram duas horas de barbárie: balas de borracha, spray de pimenta, gás lacrimogêneo, cães e helicópteros que resultaram em mais de 240 feridos fisicamente e toda uma rede de professores ferida na alma e em sua dignidade. Ao fim e ao cabo, a Lei foi votada e aprovada.

A lição que fica deste episódio, dentre outas, é a de que perde a sociedade e perde a nossa já frágil democracia. A lição dada por esses professores e professoras, porém, é a de que lutar por um direito assegurado vale sempre a pena. Em Nota, afirma o sindicato dos professores:

E assim, neste dia, apesar da resistência pacífica e heroica dos(as) servidores(as) estaduais, a tramitação do projeto do governo continuou. Ao custo de sangue e lágrimas de centenas de trabalhadores(as). E isto, sim, é de lamentar e repudiar. Além de não podermos entrar e nos manifestar na Casa do Povo, fomos expulsos violentamente das ruas. É um desrespeito ao Estado Democrático de Direito. É o retorno de uma ditadura insana, na qual a vaidade e o projeto personalista do senhor governador se sobrepõe ao de milhares de trabalhadores e trabalhadoras (APP SINDICATO).

Por que iniciar este diálogo com esta menção às greves docentes e a esse lamentável episódio? Por entender que falar em direito à educação sem mencionar a realidade estabelecida é falar no vazio. Parto do pressuposto de que a proclamação de direitos, ainda que com o risco de que se tornem "letra morta", sinaliza em direção ao direito e obrigação de lutar para que se efetivem, haja vista terem sido proclamados (CHAUÍ, 1989, p. 10; OLIVEIRA e ADRIÃO, 2013, p. 30). 
Diante da discussão pretendida, este texto aborda, guiado pela compreensão acima, a problemática do direito à educação básica e da sua universalização. Para isso, recorre ao que determinam a Constituição Federal, a Lei de Diretrizes e Bases da Educação e o Plano Nacional de Educação 2014-2024. Traz dados sobre a oferta da educação básica e os analisa à luz do princípio constitucional do direito e do dever do Estado. A partir dessa análise, discute a problemática da universalização do Ensino Médio e do acesso à escola por parte das juventudes brasileiras, conferindo destaque final às condições de oferta com qualidade na última etapa da Educação Básica.

\section{Entre o proclamado e o realizado: $O$ direito à educação na Constituição Federal e legislação decorrente}

Marilena Chauí no texto já mencionado assevera que "cada direito, uma vez proclamado, abre campo para a declaração de novos direitos e que essa ampliação das declarações de direitos entra em contradição com a ordem estabelecida" (CHAUÍ, 1989, p. 26). Pelo menos duas possibilidades de interpretação se apresentam para esta afirmação: a primeira, de que o enunciado dos direitos constrange a realidade tal como dada, a ponto de se colocar a possibilidade de que ela seja transformada e, a segunda, firma-se o reconhecimento de que o direito proclamando somente o é por um sentido de ausência.

Ainda no texto referido, prossegue a autora: "podemos, então, dizer que as declarações de direitos, 'afirmam mais' do que a ordem estabelecida permite e 'afirmam menos' do que os direitos exigem, e essa discrepância abre uma brecha para pensarmos a dimensão democrática dos direitos" (CHAUÍ, 1989, p. 26). Resta claro que no ato do enunciado do direito tem-se consciência de sua insuficiência, e mais, que uma vez proclamado e reconhecido, no horizonte estão sinalizados novos direitos ainda por serem reconhecidos e/ou proclamados. É com base nesses pontos de partida e de referência que no presente texto busco tratar do direito à educação em face da realidade estabelecida.

Em se tratando da Educação Básica, tomá-la como direito implica em compreendê-la como "educação de base, como etapas conjugadas sob um só todo", afirma Cury (2008) ao fazer referência ao texto da Lei de Diretrizes e Bases da Educação de $1996^{3}$.

A LDB 9.394/96, ao estabelecer o nível Educação Básica como sendo aquele que abrange a escolarização de zero a 17 anos, leva a compreendê-la, ao mesmo tempo, como "conceito novo" e como ampliação do "direito" (CURY, 2008). Como "conceito novo",

A educação básica veio esclarecer e administrar um conjunto de realidades novas trazidas pela busca de um espaço público novo. Como um princípio conceitual, genérico e abstrato, a educação básica ajuda a organizar o real existente em novas bases e administrá-lo por meio de uma ação política consequente (CURY, 2008, p. 294).

Entendida como direito, a Educação Básica, no contexto brasileiro, significa "um recorte universalista próprio de uma cidadania ampliada e ansiosa por encontros e reencontros com uma democracia civil, social, política e cultural" (CURY, 2008, p. 294). O constrangimento em relação ao estabelecido se verifica na medida em que desde 1971, pela Lei n 5.692, a obrigatoriedade escolar mínima no país seria de oito anos; porém, ao momento em que se consagra a LDB de 1996, portanto, 25 anos depois do proclamado, a média de escolaridade dos/das brasileiro/as acima de 18 anos era de 6,2 anos (IBGE, Séries Estatísticas. Consulta on line).

O direito proclamado na Lei de Diretrizes e Bases da Educação possui seu marco referencial ancorado na Constituição Federal (CF) de 1988. A Carta Magna traz em seu Artigo $5^{\circ}$ a educação como um direito social, ao lado da saúde, do trabalho, do lazer, da segurança, da previdência social, da proteção à maternidade e à

3 Pela LDB 9.394/96 a educação brasileira se organização em dois níveis de ensino: Educação Básica e Educação Superior. A Educação Básica compreende três etapas: Educação Infantil, Ensino Fundamental e Énsino Médio. Originalmente é proclamado como obrigatório somente o Ensino Fundamental de oito anos. Conforme a explicitação presente nas Diretrizes Curriculares Nacionais Gerais da Educação Básica, 14 anos após ter sido sancionada a LDB, a educação básica deve ser compreendida como "um conjunto orgânico, sequencial e articulado" (Brasil, Parecer CNE/CEB 07/2010 e Resolução CNE/CEB 04/2010). 
infância, e da assistência aos desamparados, tendo sido acrescidos o direito à moradia, por meio da Emenda Constitucional (EC) nº 26/2000 e o direito à alimentação, por meio da EC nº 64/2010.

No Capítulo III - "Da educação, da cultura e do desporto", na seção I - Da educação, a CF explicita em seu artigo de número 205:

A educação, direito de todos e dever do Estado e da família, será promovida e incentivada com a colaboração da sociedade, visando ao pleno desenvolvimento da pessoa, seu preparo para o exercício da cidadania e sua qualificação para o trabalho.

No Art. 206 são elencados os princípios sob os quais deve se dar a educação, dentre eles: a igualdade de condições para o acesso e permanência na escola冈 a liberdade de aprender, ensinar, pesquisar e divulgar o pensamento, a arte e o saber; o pluralismo de ideias e de concepções pedagógicas; coexistência de instituições públicas e privadas de ensino; a gratuidade do ensino público em estabelecimentos oficiais; a valorização dos profissionais do ensino; a gestão democrática da educação pública; a garantia de padrão de qualidade.

Se em meados da década de 1990 o constrangimento da realidade diante do direito proclamado impunha como exigência que se envidassem esforços no sentido da universalização do Ensino Fundamental, alçado a obrigatório dos seis aos 14 anos pela Lei no 10.172/2001 que estabelecia o Plano Nacional de Educação 2001-2011, atendida a ampliação do acesso e da permanência nesta etapa, o final dos anos 2000 anunciava a possibilidade e a necessidade de que se proclamasse novo alargamento do direito à educação. É o que sustentava a EC 59/2009 ao propor e incorporar na Constituição Federal a obrigatoriedade escolar dos 4 (quatro) aos 17 anos, indicando o ano de 2016 para que se efetive.

Originalmente, o Art. 208 da CF de 1988 assim anunciava:

0 dever do Estado com a educação será efetivado mediante a garantia de:

I ensino fundamental, obrigatório e gratuito, inclusive para os que a ele não tiveram acesso na idade própria". E, pela EC 59/2009, a Constituição Federal passa a afirmar como dever do Estado: "I - educação básica obrigatória e gratuita dos 4 (quatro) aos 17 (dezessete) anos de idade4. Desde a EC 14 de 1996 se tem assegurada a oferta gratuita para todos os que não tiveram acesso à educação escolar na idade própria5.

Entre o proclamado e o realizado: o constrangimento da Constituição Federal diante da ordem estabelecida Nesta seção, buscarei elucidar o argumento de que os direitos proclamados entram em contradição com a ordem estabelecida (CHAUÍ, 1989, p. 26). Para esse fim, irei recorrer a dados quantitativos e características da oferta das etapas da Educação Básica.

De acordo com os dados do Censo da Educação Básica de 2012, a matrícula na pré-escola neste ano era de 4.754.72, configurando um crescimento de 1,6\%, em relação a 2011, que contava com 4.681 .345 matriculados. Em 2011, esse total significava pouco mais de $80 \%$ da coorte. No entanto, se consideramos que a faixa de quatro e cinco anos é idade escolar obrigatória e se considerarmos ainda que a população brasileira em 2011 nessa idade era de 5.698.280, constataremos uma defasagem de oferta na ordem de 1.016.935 matrículas.

Para o Ensino Fundamental, 2011 contava com um total de 30.358.640 matrículas, sendo 16.360.770 nos anos iniciais (6 a 10 anos) e 13.997.870 nos anos finais (11 a 14 anos). A população brasileira era, nas respectivas faixas etárias e segmentos, de 15.252.392 (6 a 10 anos) e de 14.011 .623 (11 a 14 anos). Esse quadro evidencia o quanto a reprovação, a repetência e a desistência escolar são marcas do sistema educacional do país, haja vista que a matrícula no primeiro segmento do Ensino Fundamental ultrapassava em aproximadamente um milhão o número de crianças entre seis e dez anos de idade. Já para o segundo segmento, se a distorção idade série para a faixa dos 11 aos 14 anos é menor, ainda que exista, ela é imensa para a faixa etária que compreende os jovens adolescentes que têm entre 15 e 17 anos. Estavam matriculados entre o sexto e nono

4 A ampliação da obrigatoriedade está incorporada na LDB 9.304/96 por meio da Lei nº 12.796/2013.

$50 \S 1^{0}$ do Artigo 208 da CF proclama ainda que o “ acesso ao ensino obrigatório e gratuito é direito público subjetivo”. A esse respeito, ver Oliveira e Adrião (2013). 
ano do Ensino Fundamental, em 2011, um total de 3.927.758 alunos, quase 40\% das pessoas com 15, 16 ou 17 anos, o que confirma a persistência da prática da reprovação, repetência e desistência escolar.

Ainda por referência o ano de 2011, a matrícula no Ensino Médio contava com 8.400.689, considerando todas as faixas etárias e as modalidades regular e Ensino Médio Integrado ${ }^{6}$. A população em idade escolar obrigatória desejável para esta etapa era de 10.424.700 (15 a 17 anos). Destes, 5.451.576 estavam matriculados no Ensino Médio, em torno de 50\%, portanto. Se consideramos os jovens/adolescentes de 15 a 17 anos que se encontravam ainda no Ensino fundamental (3.927.758), nos deparamos com o triste número de 1.045.366 pessoas sem qualquer vínculo escolar, ainda que sejam portadores do pleno direito à educação.

Em 2012, segundo a PNAD, eram 2.464.422 os jovens de 15 a 17 anos matriculados no Ensino Fundamental regular, totalizando 23,6\% da faixa etária, e 147.676 matriculados na Educação de Jovens e Adultos $(1,45)$. Tomando ainda por referência a PNAD 2012, o número de matriculados no Ensino Médio modalidade Educação de Jovens e Adultos, nessa faixa etária contavam 20.356 pessoas ( $0,2 \%$ da faixa etária). Estavam sem estudar e não haviam concluído o Ensino Médio um total de 1.578 .562 jovens entre 15 e 17 anos, o que corresponde a 15,2\% das pessoas com idade entre 15 e 17 anos. Esses dados evidenciam os itinerários descontínuos a que está submetida a escolarização da juventude e trazem à tona o descompasso entre o proclamado e o efetivamente realizado.

Entre os anos de 2011 e 2013, a situação pouco se altera pelas etapas da Educação Básica. Em 2013, a matrícula na Educação Infantil para a faixa etária de 4 e cinco anos era de 4.860.481. Nos anos iniciais do Ensino Fundamental, em 2013, o Censo da Educação Básica trazia 15.764.926 matrículas e 13.304.355 matriculas nos anos finais. Totalizavam 8.312.815 as matrículas no Ensino Médio em 2013, considerando todas as faixas etárias. A tabela abaixo permite constatar uma tendência de (pequeno) aumento da matrícula na Educação Infantil para a faixa de quatro e cinco anos e de queda da matrícula nos dois segmentos do Ensino Fundamental e no Ensino Médio

Tabela 1: Matrículas na Educação Básica por etapas e segmentos - 2011-2013

\begin{tabular}{|c|c|c|}
\hline & 2011 & 2013 \\
\hline Pré-escola (4-5 anos) & 4.681 .345 & 4.860 .481 \\
\hline EF (6-10 anos) & 16.360 .770 & 15.764 .926 \\
\hline EF (11-14 anos) & 13.997 .870 & 13.304 .355 \\
\hline EM (Todas as faixas) & 8.400 .689 & 8.312 .815 \\
\hline
\end{tabular}

Fonte: Censo da Educação Básica, 2011 e 2013.

A tendência de queda sinaliza para a necessidade de que se analisem suas causas. Para o Ensino Fundamental, por exemplo, o que significa a queda na matrícula? Significaria algum acomodamento, haja vista o crescimento efetivo entre 1995 e 2011? Em 1995, a taxa líquida ${ }^{7}$ da matrícula no Ensino Fundamental totalizava 85,9\% e, em 2011, compunha 93,7\%, considerando a faixa etária de 7 a 14 anos, e 95,2\% a faixa etária de 6 a 14 anos (Anuário Brasileiro da Educação Básica, 2014). De qualquer modo, se consideramos que desde 1971 a idade de 7 a 14 anos compreende o tempo de escolaridade obrigatória, é possível, em face desses dados, dimensionar a distância entre o proclamado, o efetivamente realizado e o esforço que se há de fazer para que

6 Trata-se da Educação Profissional Técnica de Nível Média de oferta integrada ao Ensino Médio. Para efeitos de contagem da matrícula, o censo escolar considera o Ensino Médio regular, não profissional e, também, o Ensino Médio Integrado.

7 Taxa de Escolarização, conforme conceitua o Instituto Brasileiro de Geografia e Estatística, é "a percentagem dos estudantes (de um grupo etário) em relação ao total de pessoas (do mesmo grupo etário), podendo ser líquida ou bruta". A taxa de escolarização líquida refere-se à parcela da população na faixa etária matriculada na etapa/série esperada e taxa bruta mostra se a oferta de matrícula é suficiente para atender a demanda na faixa etária/etapa desejada. 
se tenha o direito plenamente assegurado e uma aproximação mais efetiva em relação à universalização.

No que diz respeito ao Ensino Médio, os dados sinalizam para um quadro ainda mais preocupante, pois apontam para uma crescente retração quando comparados à evolução das matrículas ocorrida entre 1991 e 2004 e ao movimento ocorrido no Ensino Fundamental entre 2000 e 2011. As matrículas no Ensino Médio cresceram de 3.772 .330 em 1991 para 8.401 .829 em 2011. Um crescimento da ordem de mais de $50 \%$ em dez anos. O ápice do crescimento ocorreu em 2004, com 9.169.357. Desde então, verifica-se uma oscilação para mais ou para menos entre 2005 e 2013.

Para o Ensino Médio, a taxa líquida de matrícula era de 23,5\% em 1995, passando a 54,4\% em 2012. Verificase, por um lado, uma significativa expansão, e, por outro, uma imensa distância com relação à universalização. A redução da matrícula está concentrada nos jovens de 18 a 24 anos (é maior para o segmento de 20 a 24 anos), na rede pública estadual; é maior na Região Sudeste, especialmente nas grandes metrópoles, portanto, majoritariamente urbana; pouco maior no segmento masculino e proporcionalmente maior no noturno (ANUÁRIO BRASILEIRO DE EDUCAÇÃO BÁSICA, 2014).

Consideradas as limitações do presente texto, deixo indicada a necessidade de aprofundamento na caracterização da oferta da Educação Básica. Por exemplo, se levarmos em conta a distribuição regional pelo país, é possível identificar outros aspectos de uma realidade marcada pela desigualdade e heterogeneidade. Em 2012, pouco mais de 42\% da matrícula do Ensino Médio encontrava-se na região sudeste, ao passo que a região norte comportava menos do que $10 \%$ do total das matrículas. Entre os $25 \%$ mais ricos, $75 \%$ da faixa etária entre 15 e 17 anos cursavam a última etapa da Educação Básica. Já entre os 25\% mais pobres, a matrícula atende a pouco mais de 40\%. Entre os autodeclarados brancos, 62\% cursavam o Ensino Médio em 2012. Entre os autodeclarados pretos, as matrículas estavam na casa dos 45\% (IBGE/PNAD, 2012).

Nesse cenário de expansão, algumas características vão se instituindo e caracterizando a oferta, o acesso e a permanência na escola. Embora a ampliação do acesso venha se efetivando nas duas últimas décadas, as distorções idade/série permanecem como marca do sistema educacional brasileiro. No que se refere à faixa dos 15 aos 17 anos de idade, como visto, aproximadamente 40\% dos estudantes encontram-se ainda no Ensino Fundamental. Esse cenário sinaliza também para as desigualdades de acesso e permanência. Em vista disso, a consolidação dos direitos depara-se e se debate com o constrangimento provocado pela ordem estabelecida, ao mesmo tempo em que novos direitos são proclamados.

\section{Mais uma vez a proclamação de direitos: o Plano Nacional de Educação 2014-2024 e a universalização da Educação Básica}

Após amplo debate nacional marcado pelas conferências municipais, estaduais e pela Conferência Nacional de Educação - CONAE 2010 e por aproximadamente três longos anos de idas e vindas ao Congresso Nacional, em junho de 2014 foi finalmente aprovado pelo legislativo e sancionado sem vetos o Plano Nacional de Educação com vigência entre 2014 e 2024 (BRASIL, LEI 13.005/2014).

Em suas diretrizes gerais, a Lei do PNE sinaliza para o reconhecimento dos limites da ordem estabelecida em face dos direitos já proclamados. Além disso, aponta para ações no campo das políticas públicas que venham ao encontro da necessidade de que os direitos proclamados sejam, de fato, assegurados.

São diretrizes do Plano Nacional de Educação estabelecidas na Lei 13.005 de 25 de junho de 2014, Artigo $2^{\circ}$ :

I - erradicação do analfabetismo;

II - universalização do atendimento escolar;

III - superação das desigualdades educacionais, com ênfase na promoção da cidadania e na erradicação de todas as formas de discriminação;

IV - melhoria da qualidade da educação; 
V - formação para o trabalho e para a cidadania, com ênfase nos valores morais e éticos em que se fundamenta a sociedade;

VI - promoção do princípio da gestão democrática da educação pública;

VII - promoção humanística, científica, cultural e tecnológica do País;

VIII - estabelecimento de meta de aplicação de recursos públicos em educação como proporção do Produto Interno Bruto - PIB, que assegure atendimento às necessidades de expansão, com padrão de qualidade e equidade;

IX - valorização dos (as) profissionais da educação;

$X$ - promoção dos princípios do respeito aos direitos humanos, à diversidade e à sustentabilidade socioambiental.

Das diretrizes estabelecidas se depreende o reconhecimento de direitos já incorporados à legislação; porém, ainda não efetivamente assegurados, desde a superação do analfabetismo, que acomete ainda próximo a 2\% (166, 8 mil) de jovens adolescentes entre 15 e 17 anos de idade. Em 2011, o país possuía a triste marca de 12,9 milhões de pessoas com mais de 15 anos analfabetas, conforme os dados da PNAD. Aliado ao cenário visto na seção anterior, esse quadro ajuda a compreender o porquê das palavras fortes na descrição das diretrizes do novo PNE: universalização, superação das desigualdades, melhoria da qualidade e valorização dos profissionais da educação são algumas delas.

Em vista do cumprimento dessas diretrizes, o anexo da Lei 13.005/14 traz dentre as suas metas a universalização da Educação Básica, particularmente no que se refere à faixa etária obrigatória8:

- Meta 1: universalizar, até 2016, a Educação Infantil na pré-escola para as crianças de 4 (quatro) a 5 (cinco) anos de idade e ampliar a oferta de Educação Infantil em creches de forma a atender, no mínimo, 50\% (cinquenta por cento) das crianças de até 3 (três) anos até o final da vigência deste PNE.

- Meta 2: universalizar o Ensino Fundamental de 9 (nove) anos para toda a população de 6 (seis) a 14 (quatorze) anos e garantir que pelo menos 95\% (noventa e cinco por cento) dos alunos concluam essa etapa na idade recomendada, até o último ano de vigência deste PNE.

- Meta 3: universalizar, até 2016, o atendimento escolar para toda a população de 15 (quinze) a 17 (dezessete) anos e elevar, até o final do período de vigência deste PNE, a taxa líquida de matrículas no Ensino Médio para 85\% (oitenta e cinco por cento).

Em que sentido podemos tomar o termo "universalização"? Tornar "universal" sem que seja mera figura retórica implica em pelo menos três ações por parte do poder público: o reconhecimento do direito; a ampliação da oferta de modo a alcançar a maior proximidade possível em relação à taxa líquida de escolarização; e que se assegure o caráter obrigatório e gratuito.

Em linhas gerais, a caracterização da oferta do Ensino Médio brasileiro atualmente parte dos seguintes dados (ano de referência 2013 conforme o Censo da Educação Básica).

- 24,2 mil escolas

- 413 mil Professores

- 8,3 milhões de estudantes no Ensino Médio

- 1,3 milhões de estudantes na EJA

- 10,4 milhões de jovens adolescentes de 15 a 17 anos

- 21 milhões de jovens e adultos como demanda potencial

Trata-se de uma oferta majoritariamente pública e estadual. Das 8.312.6815 matrículas de Ensino Médio em 2013, 12,2 \% estavam na rede privada, $85,5 \%$ nas redes estaduais e apenas $1 \%$ na rede federal. Outro dado expressivo diz respeito à distribuição das matrículas entre os turnos. Se em 1995 as matrículas estavam 34\% no diurno e 66\% no noturno, conforme os dados do censo escolar daquele ano, em 2011 essa relação se inverte,

8 Abordarei, dada a finalidade e limitação do presente texto, apenas a meta 3 do Plano Nacional de Educação, que trata do tema da universalização do Ensino Médio, haja vista alimentar a discussão a ser feita na próxima seção do artigo. Menciono as metas 1 e 2 por tratarem, igualmente, da temática da universalização. 
passando a 67,5\% das matrículas no período diurno e uma retração da matrícula noturna, totalizando 32,5\%, de acordo com os dados do Censo Escolar 2011.

Em se tratando da escolarização dos jovens de 15 a 17 anos, entendo que o ponto de partida e referência permanente para dimensionar o desafio da universalização está ancorado em duas ordens de questões: a situação educacional atual da juventude e a consideração de que não estamos diante de uma, mas de várias "juventudes".

Sobre a questão de primeira ordem, o quadro abaixo permite visualizar a situação educacional da juventude:

\section{Quadro I - Situação Educacional da Juventude - 15 a 17 anos e 18 a 24 anos - 2012}

\begin{tabular}{|c|c|c|}
\hline Situação/escolaridade & 15 a 17 anos & 18 \\
\hline Analfabetos & $1,6 \%$ & 24 anos \\
\hline Frequentam a escola & $81,3 \%$ & $31,7 \%$ \\
\hline Ensino Fundamental & $25,3 \%$ & $4,9 \%$ \\
\hline Ensino Médio & $54,6 \%$ & $13,8 \%$ \\
\hline Educação Superior & $1,4 \%$ & $12,9 \%$ \\
\hline Não frequentam a escola & $18,7 \%$ & $68,3 \%$ \\
\hline Total (mil) & $10.417,9(100 \%)$ & $24.284,7(100 \%)$ \\
\hline
\end{tabular}

Fonte: IBGE 2010 (dados populacionais) e PNAD 2012 (dados educacionais)

Tendo por base os dados do Censo da Educação Básica de 2013 e considerando a Meta 3 do PNE com vistas à universalização do Ensino Médio, temos o panorama a seguir:

2013: $84,2 \% \quad$ Meta 2023: $100 \%$

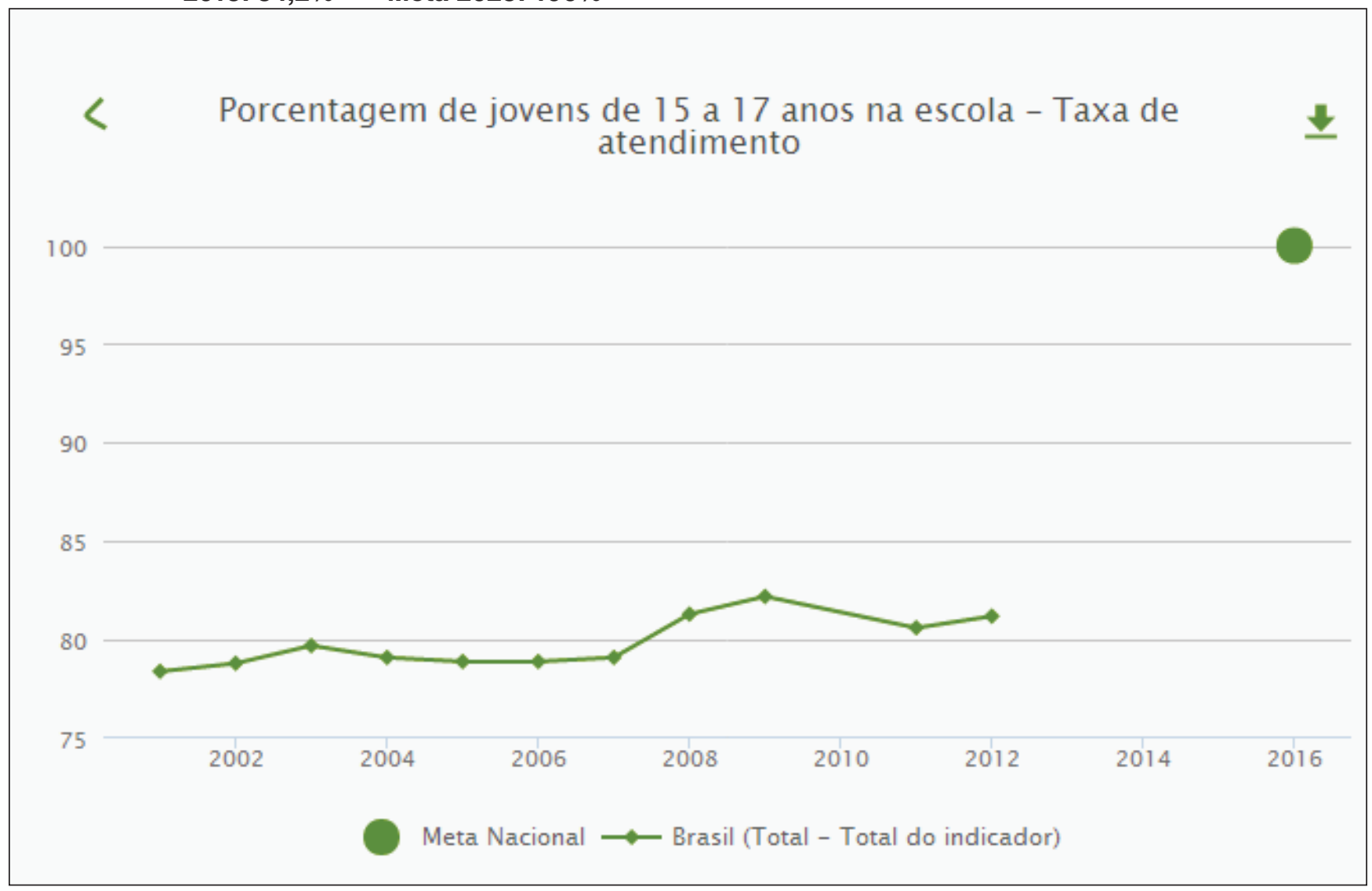


2013: $54,4 \%$

Meta 2023: 85\%

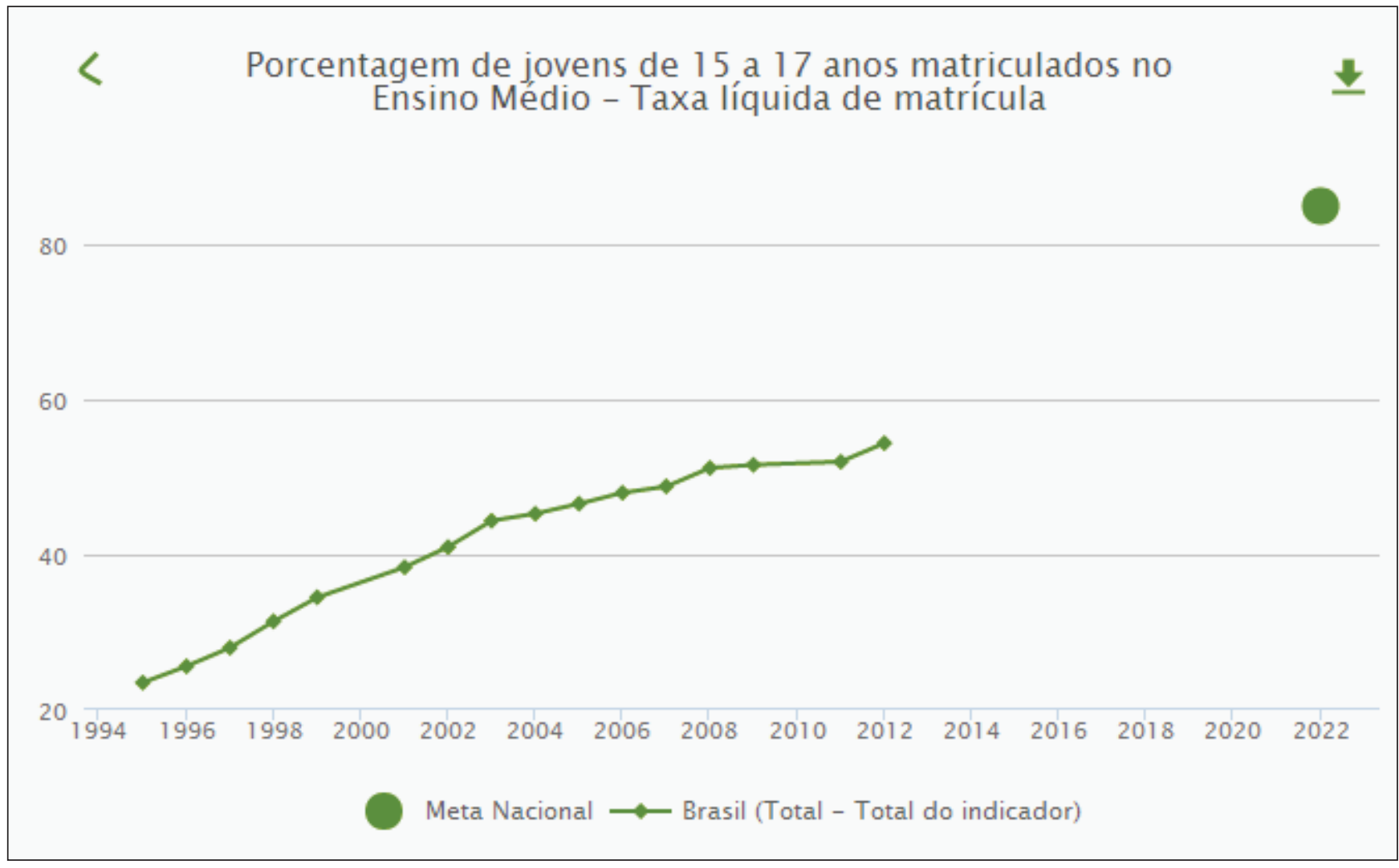

Os gráficos acima permitem dimensionar quantitativamente a distância entre o já assegurado e a meta de universalização para o período estabelecido no Plano Nacional de Educação. Levando em conta o sentido da universalização como direito associado à obrigatoriedade e gratuidade, é possível afirmar que estamos diante do reconhecimento do direito, porém, de um direito constrangido pela ordem estabelecida, marcada pela necessidade de ampliação da oferta, de melhoria da qualidade, de investimento nas condições da docência e das condições materiais das escolas, conforme explicitado nas diretrizes do PNE 2014-2024.

O segundo ponto a considerar, o de que não estamos diante de uma, mas de várias "juventudes", remete, por um lado, à necessidade de superação de um amálgama cultural que, cravado na história, ainda hoje impele ao não reconhecimento por parte da sociedade brasileira, especialmente entre os mais pobres, de que o Ensino Médio se institui como um direito. Por outro lado, essa mesma história que levou à identificação de um ensino para poucos provoca um tensionamento ao não reconhecer que entre os muros da escola se espraia uma multiplicidade de juventudes, sim, com "s", uma juventude plural. Plural nos desejos, nas expectativas, nos interesses. Plural nas formas de ver e viver. Plural e desigual diante das condições de produção material da existência. Plural e diversa diante dos projetos de futuro. Plural porque diferentes na cor, na sexualidade, nas crenças, etc.

Essa pluralidade de juventudes traz para as escolas tensões que a obrigam a rever as práticas de padronização dos modos de ensinar e de avaliar. Faz, também, com que emerja a necessidade de que se produzam diálogos mediados por outras linguagens, outras artes, outros modos de compreender e interagir com os campos da ciência, da ética, da estética, do trabalho, da tecnologia.

Assim, vale considerar, em se tratando da melhoria da qualidade, como afirma o PNE, as situações escolares marcadas pela reprovação e desistência. No que diz respeito ao Ensino Médio, os dados sugerem especial atenção, haja vista a continuidade de uma realidade que se prolonga anos a fio. Para ilustrar essa condição, tomo por referência os dados de abandono e reprovação no ano de 2012. A taxa média de reprovação no Ensino 
Médio foi de 12,5\%, com uma variação significativa entre as 27 unidades da federação, sendo a menor taxa a de 6\%, no Amazonas, e a maior taxa a de 20,7\%, no Rio Grande do Sul. Em 18 unidades da federação, mais de 10\% dos estudantes reprovaram neste ano. A taxa de abandono em 2012 ficou em torno dos $12 \%$ na média nacional, marcada igualmente por grande oscilação entre redes estaduais, sendo a menor a de 4,5\%, em São Paulo, e a maior, 19,3\%, no Rio Grande do Norte.

Dessa breve contextualização sobre a abrangência e condições de oferta do Ensino Médio, reitero a finalidade de dimensionar a distância entre os direitos proclamados na Constituição Federal e na Lei de Diretrizes e Bases da Educação, bem como nos enunciados das Diretrizes e Metas do Plano Nacional de Educação. O constrangimento em face da "ordem estabelecida" (CHAUÍ, 1989, p.26) indica como oportuno problematizar as possibilidades de aproximação do estabelecido em relação aos direitos anunciados. Esse exercício é o que me proponho a fazer a seguir.

\section{Ensino Médio como educação básica: desafios do reconhecimento do direito e da universalização}

A heterogeneidade da matrícula e das condições de acesso e permanência, o quadro de reprovação e abandono escolar e o horizonte da universalização configuram grandes desafios à consolidação do Ensino Médio como educação básica. Em vista deles, é preciso atentar, dentre outros, para os aspectos ligados ao financiamento público. A ampliação da vinculação de recursos e a complementação financeira por parte da União, verificada com a criação do Fundo de Manutenção e Desenvolvimento da Educação Básica e de Valorização dos Profissionais da Educação (FUNDEB) a partir de 2007, pode ter se instituído como incentivo para o crescimento da oferta de vagas. Mas, em que medida o aumento do financiamento público implicou na ampliação do acesso e na melhoria das condições de permanência e qualidade?

O decréscimo na matrícula, a reprovação e o abandono escolar apontam que é preciso ainda assegurar escolas em condições plenas de realizar uma educação de qualidade, que acolham e que permitam a vivência de uma experiência formativa plena e significativa. As condições materiais não podem ser pensadas dissociadas das lógicas de organização pedagógica e curricular. É preciso, também, superar uma forma escolar estabelecida quando o "secundário" era ainda destino de poucos, marcadamente das "elites condutoras do país", conforme afirmava Gustavo Capanema na Exposição de Motivos que levou à criação das Leis Orgânicas do Ensino Secundário, em 1942.

Trata-se, portanto, de assegurar o direito à educação básica em sua plenitude, isto é, como um "todo" (CURY, 2008). Enquanto "parte" desse "todo" implica em que se alicerce o Ensino Médio, última etapa da Educação Básica, em torno de uma formação que confira a cada um/cada uma certa identidade, por um lado, e a diferença, por outro, de modo a nos reconhecermos ao mesmo tempo como "sociedade" e como "indivíduos" (Adorno, 1996). E ainda, que a escola possa se instituir como espaço capaz de minimizar os efeitos produzidos pelas condições desiguais de existência e que, ao mesmo tempo, se guie pela construção da autonomia intelectual e moral, tendo em vista compreender e agir criticamente no mundo.

Diante desses desafios, uma pergunta a se fazer é certamente esta: Que condições de oferta e qualidade ${ }^{9}$ seriam necessárias com vistas a assegurar esse direito?

Tentarei a seguir destacar algumas situações sobre as quais julgo interessante que nos debrucemos para pensar a relação entre a consolidação do Ensino Médio como educação básica e as condições de oferta e qualidade, haja vista as contradições entre direitos proclamados e direitos assegurados e/ou efetivados.

9 Em concordância com Oliveira e Adrião (2013, p. 31), "de um lado, o pré-requisito para se discutir qualidade da educação é que esta seja para todos (quantidade), e, de outro, a qualidade é pré-requisito para se discutir a quantidade". Com essa compreensão, entendo que nos potencializamos a não sucumbir na falsa polarização de que uma (qualidade/quantidade) exclui a outra. 
Tendo como premissa que o Ensino Médio é um direito, eu começaria por trazer à reflexão a necessidade de construção de escolas e da melhoria nas condições materiais das já existentes. Aqui reitero questões ligadas ao financiamento público, tendo em vista assegurar as condições de qualidade no sentido de recuperar os edifícios escolares muitos deles em situação de abandono e construir novas escolas a partir de um projeto arquitetônico que considere as necessidades postas hoje pelos sujeitos - dessas múltiplas e plurais juventudes - que se utilizam do espaço-tempo escolar.

Com relação à infraestrutura e condições materiais das escolas de Ensino Médio, em face das diretrizes do PNE de melhoria da qualidade, vale destacar que as condições de oferta contam com $44 \%$ de escolas sem bibliotecas, $56 \%$ sem laboratórios de ciências, 7\% sem qualquer tipo de acesso à internet, 30\% sem quadras de esportes (INEP, Censo Escolar, 2012).

Nesse aspecto entram as características de materiais e equipamentos - quais linguagens desses materiais e equipamentos seriam necessárias com vistas a estabelecer uma interlocução profícua com os jovens e com os adultos que frequentam o Ensino Médio atualmente? Um exemplo é da necessidade de rede wireless em cada escola como condição de assegurar a todos/as, alunos/as e professores/as as condições plenas de comunicação e interação com o mundo virtual.

Não podemos nos esquecer de que as tecnologias e suas redes interativas são fatores de construção identitária dos jovens que, por essa razão, atribuem (ou não) sentido e significado ao espaço da escola. A mediação dessas tecnologias pode se configurar, portanto, em formas de ressignificar as mediações estabelecidas entre professores/as e alunos/as, dentre outros aspectos.

Essas condições, no entanto, não podem ser pensadas dissociadas das lógicas de organização curricular. Urge estabelecer uma organização pedagógico-curricular que considere enfrentar a cultura escolar consolidada que reitera a fragmentação e a hierarquização dos saberes, a separação entre teoria e prática, a perspectiva de processos de ensino e aprender centrados quase que exclusivamente na memorização. Em vista disso, merecem destaque as proposições das Diretrizes Curriculares Nacionais para o Ensino Médio (Brasil, DCNEM, Parecer CNE/CEB 05/2011 e Resolução CNE/CEB 02/2012) que sinalizam para uma abordagem curricular integrada e integradora das áreas do conhecimento e dos componentes curriculares apropriados para a última etapa da Educação Básica.

Outro aspecto a considerar neste exercício de pensar processos que possam ir ao encontro do reconhecimento e consolidação do direito ao Ensino Médio diz respeito à ampliação do acesso e à contenção da reprovação e do abandono escolar. A ampliação do acesso precisa levar em conta a heterogeneidade de distribuição da matrícula, de acesso e permanência entre as regiões do país. A situação de abandono e/ou reprovação passa, certamente, por compreender suas razões: O que estaria levando largos contingentes de jovens a desistir da escola? Essa pergunta nos coloca face a face com a necessidade de conhecer as causas do abandono e do que os levaria a permanecer. As respostas sinalizam para uma reconfiguração dos sentidos da escola, pela compreensão do conhecimento (escolar) como dimensão explicativa e crítica da realidade, dentre outras (SILVA, PELISSARI, STEIMBACH, 2013).

Nessa perspectiva, temos que considerar ainda a multiplicidade de formas de viver a juventude: por exemplo, temos no Brasil hoje 50\% de jovens de 18 a 24 anos que só trabalham; temos quase 20\% de jovens de 15 a17 anos que estudam e trabalham (IBGE, PNAD 2012). Essas e outras características da juventude brasileira nos levam a indagar: quais as condições de oferta que permitem atender a essa diversidade, seja ela na relação dos jovens com o trabalho, seja com relação às regiões do país, seja com relação a outras características que definem a juventude branca, negra, indígena, urbana e rural, do centro e das periferias, das suas diferentes escolhas e identidades que clamam pelo combate ao racismo, à homofobia, etc... Que condições de oferta e estrutura são capazes de manter nossos estudantes nas escolas e assegurar uma formação integral plena que não reproduza o preconceito, a discriminação e a indiferença em relação ao outro? 
Certamente essas questões vão ao encontra da problemática da formação inicial e continuada de professores, ainda que não se esgote nela. Temos um conjunto de políticas atualmente que buscam valorizar a formação de professores, dentre eles o Plano Nacional de Formação de Professores da Educação Básica - PARFOR, o Programa Institucional de Iniciação à Docência - PIBID e o Pacto Nacional pelo Fortalecimento do Ensino Médio. Sem dúvida, são ações de grande relevância, porém insuficientes. Para atender aos grandes desafios postos para o Ensino Médio hoje, precisamos ainda nos perguntar: De qual projeto de formação de professores precisamos? Certamente a resposta a essa pergunta passa pela necessidade de uma formação que considere as várias juventudes que temos e teremos em nossas escolas; que as instituições formadoras enfrentem internamente a eterna hierarquia entre bacharelado e licenciatura, o primeiro sempre considerado mais nobre, mais valorizado; que mergulhe o futuro professor no universo da escola e da sala de aula e que o fortaleça por meio de uma sólida formação teórica e prática.

Sobre a formação continuada, uma condição fundamental que confere identidade à função docente precisamos estudar permanentemente, qual perspectiva nos aproximaria das melhores condições de oferta? De certo não é aquela no formato de eventos esporádicos, mas uma que permita adentrar com algum grau de profundidade o universo escolar e social e encontrar os caminhos que possibilitem, com alguma segurança, enfrentar os desafios que vão sendo trazidos para dentro do espaço-tempo escolar.

Ao falar em condições de oferta e qualidade, não poderia deixar de pensar que toda formação será insuficiente se não estiverem asseguradas as melhores condições em que a docência se realiza. E aqui temos que nos lembrar desde o tempo até a forma dos contratos de trabalho; a formação em serviço na escola e fora dela, os salários, a saúde, etc...

Sobre a docência em nosso país, com base em Nota Técnica elaborada pelo DIEESE (2014) ${ }^{10}$, é possível identificar algumas características preponderantes. O Brasil a tem como uma profissão essencialmente feminina, haja vista que em 2013 a função era exercida na ordem de 83,1\% por mulheres. Observa-se em períodos recentes o ingresso mais tardio na profissão, por volta dos 26 anos de idade. Do mesmo modo, a condição de maior estabilidade está concentrada em uma faixa etária superior, em média aos 35 anos de idade. Este último dado sugere a persistência de vínculos de trabalho precários, sobretudo no início da carreira. Quanto à jornada de trabalho, a maioria dos vínculos é de 36 a 40 horas semanais, 41,3\%, seguido dos contratos de 20 a 25 horas, $32 \%$. Por fim, o rendimento médio mensal dos professores brasileiros para jornadas de 30 horas, em 2013, era de $R \$ 1.762,23$, o que representa $43 \%$ da composição da renda familiar. Conforme a Nota Técnica do DIEESE, "a remuneração do professor permanece em desvantagem em relação às demais carreiras e, para reverter a desvalorização, será necessário manter uma política salarial que garanta ganhos reais aos servidores (DIEESE, 2014, p. 11). Em vista desses dados, é possível dimensionar o alcance que deverão ter as ações de política pública no que se refere à melhoria das condições docentes em face das metas e diretrizes postas pelo atual Plano Nacional de Educação.

Por fim, julgo importante lembrar que quaisquer propostas de mudanças que desconsiderem as condições para sua materialidade será imediatamente letra morta, e isso passa pelo reconhecimento dos espaços escolares e de seus interlocutores como locus central e estratégico das transformações que queremos e precisamos para o Ensino Médio brasileiro.

Tendo em vista que "as declarações de direitos 'afirmam mais' do que a ordem estabelecida permite e 'afirmam menos' do que os direitos exigem, abrem brechas para pensarmos a dimensão democrática dos direitos" (Chauí, 1989, p. 26). E, considerando que é no hiato que se estabelece entre um e outro que nos movemos e nos mobilizamos, esta seção buscou apontar o que entendo como possíveis viáveis no contexto da educação e da sociedade brasileira de hoje.

10 DIEESE. Departamento Intersindical de Estatística e Estudos Econômicos. Nota Técnica. Transformações recentes no perfil docente das escolas estaduais e municipais de educação básica. NT nº 141. Outubro de 2014. 


\section{Palavras finais, sem, no entanto, dar a conversa por encerrada...}

Diante das situações expostas e que escolhi trazer à nossa reflexão, eu termino esta intervenção convidando a poeta Cora Coralina a compor comigo essas palavras finais. E aqui, particularmente me dirijo a todos/as professores e professoras do Brasil, particularmente aos violentados em seus direitos e que, ainda assim, se esforçam no intento de mostrar e transformar os sentidos da escola para as nossas crianças e jovens:

Não te deixes destruir...

Ajuntando novas pedras e construindo novos poemas.

Recria tua vida, sempre, sempre. Remove pedras e planta roseiras e faz doces. Recomeça.

Faz de tua vida mesquinha um poema.

E viverás no coração dos jovens e na memória das gerações que hão de vir.

(Cora Coralina, Aninha e suas pedras, Outubro, 1981).

\section{Referências}

ADORNO, T. Teoria da semicultura. In: Educação \& Sociedade. ano XVII, n. 56, dezembro/1996.

Anuário Brasileiro da Educação Básica 2014. Disponível em http://www.todospelaeducacao.org.br/ biblioteca/1493/anuario-brasileiro-da-educacao-basica-2014/ Acesso em 30/04/2014.

APP Sindicato dos Professores do Estado do Paraná. Nota da APP Sindicato do dia 29 de abril de 2015. Disponível emhttp://www.diariodosudoeste.com.br/politica/2015/04/manifestacao-acaba-em-confronto-emcuritiba/1392080/ Acesso em 30/04/2015.

BRASIL. Constituição da República Federativa do Brasil. (atualizada). Disponível em http://www. planalto.gov. br/ccivil_03/Constituicao/Constituicao.htm. Acesso em 25/04/2015

BRASIL. CONSTITUIÇÃO. Emenda Constitucional n. 59, de 11 de novembro de 2009. Acrescenta $\S 3^{\circ}$ ao art. 76 do Ato das Disposições Constitucionais Transitórias; dá nova redação aos incisos I e VII do art. 208, ao $\S 4^{\circ}$ do art. 211 e ao $\S 3^{\circ}$ do art. 212 e ao caput do art. 214, com a inserção neste dispositivo de inciso VI, da Constituição Federal. Diário Oficial da República Federativa da União, Brasília, DF, 11 nov. 2009. Disponível em: http://www.planalto.gov.br/ccivil_03/constituicao/Emendas/Emc/emc59.htm>. Acesso em 26/04/2015

BRASIL. Lei n 10.172 de 09 de janeiro de 2001. Aprova o Plano Nacional de Educação 2001 2010. Disponível em http://www.planalto.gov.br/ccivil_03/LEIS/LEIS_2001/L10172.htm Acesso em 26/04/2015.

BRASIL. Lei no 13.005 de 24 de junho de 2014. Aprova o Plano Nacional de Educação 2014-2024. Disponível em http://www2.camara.leg.br/legin/fed/lei/2014/lei-13005-25-junho-2014-778970-publicacaooriginal-144468pl.html. Acesso em 30/04/2015.

BRASIL. Lei de Diretrizes e Bases da Educação. LDB no 9.394/96 (atualizada). Disponível em http://www. planalto.gov.br/ccivil_03/LEIS/L9394.htm. Acesso em 15/05/15.

BRASIL, Conselho Nacional de Educação. Câmara da Educação Básica. Parecer CNE/CEB 07/2010 e Resolução CNE/CEB 04/2010. Diretrizes Curriculares Nacionais Gerais para a Educação Básica. Disponível em http://portal.mec.gov.br/index.php?option=com_content\&id=12992:diretrizes-para-a-educacao-basica. Acesso em 15/05/15. 
BRASIL, Conselho Nacional de Educação. Câmara da Educação Básica. Parecer CNE/CEB 05/2011 E Resolução CNE/CEB 02/2012. Diretrizes Curriculares Nacionais para a Educação Básica. Disponível em http:// portal.mec.gov.br/index.php?option=com_content\&id=12992:diretrizes-para-a-educacao-basica. Acesso em 15/05/15.

BRASIL. IBGE. Séries estatísticas. Consulta on line, Disponível em http://www.seriesestatisticas.ibge.gov.br/ series.aspx?vcodigo=PD164. Acesso em 15/05/2015

BRASIL. IBGE. Pesquisa Nacional por Amostra de Domicílio. PNAD. 2011 e 2012. Disponível em http://ibge. gov.br/home/estatistica/populacao/trabalhoerendimento/pnad2012/default_sintese.shtm Acesso em 05/05/15.

CHAUÍ, M. Cultura e democracia. $8^{a}$ edição. São Paulo: Cortez, 1989.

CURY, C. R. J.A Educação Básica como Direito. Cadernos de Pesquisa. v. 38, n 134, mai/ago 2008.

OLIVEIRA, R. P.; ADRIÃO, T. Os 25 anos da Constituição de 1988: reflexões sobre o direito à educação de qualidade. In: LEITE, Y; Militão, S. e LIMA, V. Políticas educacionais e qualidade na escola pública. Curitiba: CRV, 2013.

SILVA, M.; PELISSARI, L.; STEIMBACH, A. Juventude, escola e trabalho. Abandono e permanência na Educação Profissional Técnica de Nível Médio. Educação e Pesquisa (USP). V. 39, n 2, p. 403-417, abr/jun 2-13.

Recebido em Abril de 2015 | Aprovado em Junho de 2015 